\title{
Methylphenidate Dose-Dependently Affects Aggression and Improves Fear Extinction and Anxiety in BALB/cJ Mice
}

\author{
Amanda Jager ${ }^{1}$, Doranda Kanters ${ }^{1 \dagger}$, Femke Geers ${ }^{1 \dagger}$, Jan K. Buitelaar ${ }^{1}$, Tamas Kozicz ${ }^{2,3}$ \\ and Jeffrey C. Glennon ${ }^{*}$ \\ ${ }^{1}$ Department of Cognitive Neuroscience, Donders Institute for Brain, Cognition and Behavior, Radboudumc, Nijmegen, \\ Netherlands, ${ }^{2}$ Department of Anatomy, Donders Institute for Brain, Cognition and Behavior, Radboudumc, Nijmegen, \\ Netherlands, ${ }^{3}$ Department of Clinical Genomics, Center for Individualized Medicine, Mayo Clinic, Rochester, MN, United States
}

OPEN ACCESS

Edited by:

Marieke Klein,

Radboud University Nijmegen Medical Centre,

Netherlands

Reviewed by: Kazuhiro Takuma,

Osaka University, Japan

Melanie P Leussis,

Emmanuel College,

United States

*Correspondence:

Jeffrey C. Glennon

jglennon77@outlook.com

tThese authors have contributed equally to this work

Specialty section:

This article was submitted to Behavioral and Psychiatric Genetics, a section of the journal

Frontiers in Psychiatry

Received: 03 June 2019 Accepted: 24 September 2019

Published: 25 October 2019

Citation:

Jager A, Kanters D, Geers F,

Buitelaar JK, Kozicz T and Glennon JC (2019) Methylphenidate Dose-Dependently Affects Aggression and Improves

Fear Extinction and Anxiety in BALB/CJ Mice.

Front. Psychiatry 10:768. doi: 10.3389/fpsyt.2019.00768
Overt aggression, increased anxiety, and dysfunctional fear processing are often observed in individuals with conduct disorder (CD) and attention-deficit hyperactivity disorder (ADHD). Methylphenidate (MPH), a psychostimulant increasing dopamine and noradrenaline tone, is effective in reducing aggression in both $C D$ and $A D H D$ individuals. However, it is unclear to which extent these effects of $\mathrm{MPH}$ are dose dependent. Here, the effects of acute intraperitoneal MPH ( 3 and $10 \mathrm{mg} / \mathrm{kg}$ ) on aggression, anxiety, social behavior, and fear extinction were investigated in BALB/cJ mice. Previous studies in BALB/cJ mice have revealed high levels of aggression and anxiety that are associated with reduced top-down cortical control. Administration of $3 \mathrm{mg} / \mathrm{kg} \mathrm{MPH}$ prolonged the attack latency and prevented escalation of aggression over time compared to vehicletreated mice, while $10 \mathrm{mg} / \mathrm{kg} \mathrm{MPH}$ increased number of bites and attacks. In addition, $3 \mathrm{mg} / \mathrm{kg}$ MPH decreased social interaction slightly. A strong anxiolytic effect was found after administration of both the 3 and $10 \mathrm{mg} / \mathrm{kg}$ doses in the elevated plus maze and the open-field test. In addition, while vehicle-treated BALB/cJ animals showed intact freezing, both doses of MPH decreased freezing to the unconditioned stimulus in a fearconditioning paradigm. A long-lasting effect on fear extinction was visible after treatment with the $10 \mathrm{mg} / \mathrm{kg}$ dose. The data support a role for MPH in the regulation of anxiety, fear processing, and aggression in BALB/CJ mice, with the latter effect in a dose-dependent manner. The findings provide a further context for examining the effects of MPH in clinical disorders such as ADHD and CD.

Keywords: aggression, animal, anxiety, attention-deficit hyperactivity disorder, conduct disorder, methylphenidate

\section{INTRODUCTION}

Children and adolescents showing aggressive and antisocial behavior are an increasing socioeconomic and societal problem, mainly due to the persistent and repeating nature of offences. In particular, heightened levels of aggression are found in children diagnosed with conduct disorder (CD), whether or not in combination with attention-deficit hyperactivity disorder (ADHD) (1). In addition to aggression, these juveniles suffer often from attention deficits, hyperactivity, impulsivity, 
increased anxiety, and abnormal fear processing (2-5). Finding the right pharmacotherapy remains challenging (6-9).

Current ADHD treatment guidelines recommend the use of methylphenidate $(\mathrm{MPH})$ as the first-line pharmacological treatment $(10,11)$. Reviews and meta-analyses indicated that MPH has moderate to large effects (effect size between 0.69 and $0.9)$ on aggression in ADHD and CD patients $(12,13)$. Conduct symptoms and aggression observed in young CD patients with co-occurring ADHD significantly improve after treatment with $\mathrm{MPH}$, independently of the severity of ADHD symptoms (14). Increased aggression can however also be an adverse effect of psychostimulant treatment, and it is unclear whether this is dose dependent (15). Furthermore, studies addressing the effect of MPH on anxiety are mixed and may depend on the state anxiety of the individual (16-19). In both human and animal studies, the dose of MPH appeared to be related to the behavioral outcome. Inverted U-shaped effects were seen after stimulant treatment in ADHD children, that is, the low dose improved memory tests, whereas the high dose significantly decreased the performance on the task (20). In mice, similarly, a low dose of MPH enhanced fear memory, whereas a high dose impaired memory (21). Other studies have shown a positive doseresponse pattern on attention and hyperactivity in children with ADHD (22). However, this was only in a subgroup of ADHD patients, as it is reported that children with ADHD without hyperactivity respond better to a low MPH dose, whereas those without hyperactivity but with higher inattention respond better to a higher dose $(22,23)$. Baseline severity of aggression, anxiety, and abnormal fear processing may play an important role in the modulation of the behavioral outcome observed in children diagnosed with these disorders.

Animal models enable us to study the effect of pharmacological interventions on a range of behaviors in a controlled environment. Most preclinical studies have shown no effect, some others anti-aggressive effects of MPH (24-26), and other studies observed anxiolytic effects of MPH (26). In addition, $\mathrm{MPH}$ was found to improve fear extinction when administered before or immediately following extinction of contextual fear (27). However, no preclinical study has investigated the effect of $\mathrm{MPH}$ dose on aggression, anxiety, and fear processing/extinction in the same animal model.

Previous research by our group has focused on the BALB/cJ mouse, an animal model that shares phenotypic traits similar to those seen in ADHD and CD, including inattention, increased aggression, and reduced social behavior (28-30). Furthermore, reversal learning with conditioned punishment revealed increased reward motivation and decreased punishment sensitivity to be present in $\mathrm{BALB} / \mathrm{cJ}$ mice, which could point towards altered DA signaling as well (Jager et al., submitted). The present study was designed to examine the effect of two doses of acute MPH administration [ 3 and $10 \mathrm{mg} / \mathrm{kg}$ intraperitoneal (i.p.)] on the behavior of BALB/cJ mice in order to answer the following questions: (1) Does $\mathrm{MPH}$ affect anxiety and fear extinction? (2) Does MPH affect social behavior and aggression, and if so, is this dose dependent? The answers to these questions will provide insights into the regulation of monoamine tone in the brain and its influences on anxiety and aggression.

\section{METHODS}

\section{Animals}

Eight-week-old male BALB/cJ mice $(n=36)$ (The Jackson Laboratory, United States) and six-week-old C57BL/6J male mice $(n=36)$ (Charles River, Germany) were used in this study. Exclusively male mice were used in order to eliminate possible variation caused by the estrous cycle of female mice. Upon entry, all mice were provided with a unique tail number. All mice were housed at the institutional animal facility in an individually ventilated cage (type 2L, Tecniplast S.p.A., Buguggiate, Italy) with an igloo as environmental enrichment and had ad libitum access to water and food. BALB/cJ mice were housed individually, and $\mathrm{C} 57 \mathrm{BL} / 6 \mathrm{~J}$ mice in groups of six mice under a reversed light/dark cycle $(12 / 12 \mathrm{~h})$ in a ventilated cabinet, Scantainer (Scanbur, Karlslunde, Denmark) with sunset at $7.00 \mathrm{am}$ at a constant temperature of $24 \pm 1^{\circ} \mathrm{C}$. All experimental procedures were approved by the Committee of Animal Experiments of the Radboud University Medical Center (project number: DEC2013-235), Nijmegen, Netherlands.

\section{Drug Administration}

MPH (Brocacef, Maarssen, Netherlands) was prepared freshly every morning of the testing and dissolved in $0.9 \%$ saline. $\mathrm{MPH}$ (3 or $10 \mathrm{mg} / \mathrm{kg}$ of body weight) or vehicle ( $0.9 \%$ saline) was delivered to BALB/cJ mice ( $n=12$ per condition) $20 \mathrm{~min}$ prior to testing by intraperitoneal (i.p.) injection. Animals were returned to their housing case until the time of testing. Injection sides were alternated in order to reduce tissue damage. The dosage of MPH administered to the mice was based on previous animal studies that have investigated locomotor activity and cognition in rodents (in details explained by 31 ). The dose of $3 \mathrm{mg} / \mathrm{kg}$ resembles the therapeutic window of treatment of ADHD in humans, while the $10 \mathrm{mg} / \mathrm{kg}$ dose may reflect more the recreational use of $\mathrm{MPH}(32,33)$. Drug administration was randomized, and experimenters were blinded to the test conditions. The blinding code was broken after the completion of the data analysis.

\section{Behavioral Tests}

All behavioral tests were carried out in the same experimental room. The experimental schedule can be found in Figure 1. Animals were transported in their cage to the room $1 \mathrm{~h}$ prior to testing. The order of testing of the mice was randomized for each of the behavioral experiments. All experiments were performed in the dark phase under red-light conditions, with the exception of the elevated plus maze, which was performed in the dark phase under dim-light conditions. No experiments were performed within the first hour after the light/dark transition. To enable testing within the first hours of darkness, the experiments were performed in three cohorts $(3 \times n=4$ per treatment group). Only the last cohort ( $n=4$ per treatment group) was tested in the circular corridor. All animals were given 1 week to acclimatize to the animal housing facility prior to behavioral testing. 


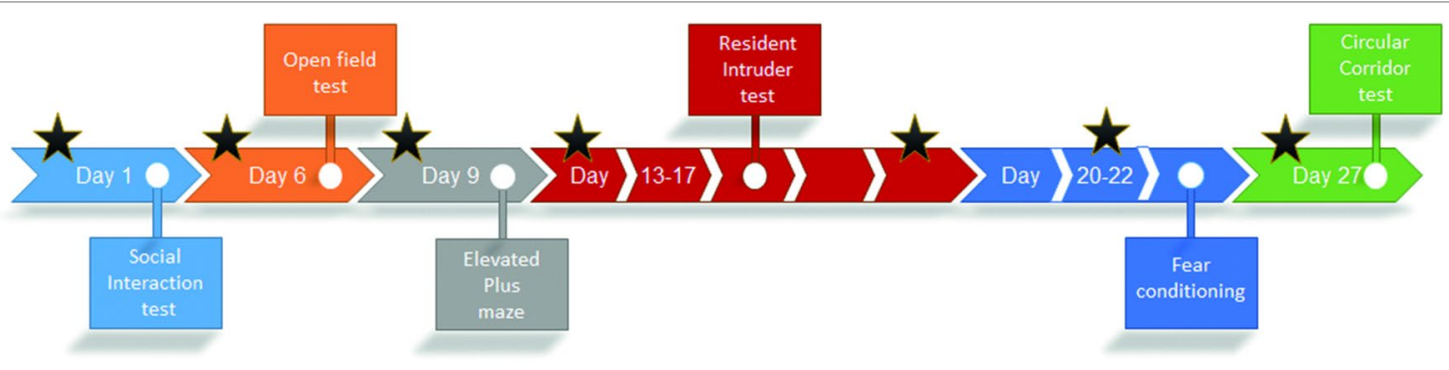

FIGURE 1 | Schedule of experimental testing. Timeline of the different experiments using BALB/cJ mice treated with $3 \mathrm{mg} / \mathrm{kg}$ methylphenidate (MPH) i.p., $10 \mathrm{mg} / \mathrm{kg}$ MPH i.p., or vehicle ( $n=12$ per group). Experiments were performed in three cohorts of four animals per condition in order to keep testing within the first hours after darkness. Drug injections were given 20 min prior to the test and are indicated by stars. During the resident-intruder test, animals were injected on day 1 and day 5 , whereas during fear conditioning, animals were only injected on day 2.

\section{Social Cognition Test}

The effect of MPH on social behavior was assessed in the social cognition test on day 1 of the experiment. Two wiremesh cylinders with large open ventilation holes $(l \times w \times h 10 \times$ $10 \times 11 \mathrm{~cm})$ were placed upside-down in a clear observation cage (dimensions $43 \times 50 \mathrm{~cm}$ ) with corn bedding material on the floor, as shown in Figure S1. An unfamiliar C57BL/6J mouse was placed under a randomly assigned cylinder. Subsequently, a BALB/cJ mouse was placed in the middle of the cage, and behavior was recorded for 5 min using a high-speed infrared camera (GigE, Basler AG, Ahrensburg, Germany). MediaRecorder (Noldus, Wageningen, Netherlands) was used to record these movies. Time spent in the social zone, which contained the cylinder with the C57BL/6J mouse, was compared to the time spent in the non-social zone. The frequency and time that the animals spent sniffing the social and non-social cylinder were analyzed as well. These behaviors were manually scored with Observer XT (Noldus, Wageningen, Netherlands).

\section{Open Field}

To assess the effect of MPH on anxiety, an open-field test was performed on day 6. Locomotion activity was quantified in a $55 \times 55 \times 36 \mathrm{~cm}$ activity chamber (made by our laboratory). The animals ( $n=12$ per group) were placed in the center of the field where locomotion activity was then recorded for 5 min. The arena was divided into four quadrants in which the connected center points of all quadrants formed the center of the field and measured $27.5 \times 27.5 \mathrm{~cm}$. The total time in the center zone, outside the center and time spent near the walls, was measured as well as the frequency of center visits. In addition, the latency to leave the center was used as an indication of nonexplorative behavior (immobility). Reduced frequency of center visits, velocity, and distance traveled were used as indications of locomotor activity and anxiety behavior. The arena was cleaned with $70 \%$ alcohol between tests. Videotapes of the locomotion activity were examined using EthoVision XT9 (Noldus, Wageningen, Netherlands).

\section{Elevated Plus Maze}

Anxiety and explorative behavior were assessed in the elevated plus maze 20 min after drug administration on day 9. The elevated plus maze (Noldus, Wageningen, Netherlands) consisted of two open $(36 \mathrm{~cm} \times 6 \mathrm{~cm})$ arms and two closed $(36$ $\mathrm{cm} \times 6 \mathrm{~cm}$, modeled with $15-\mathrm{cm}$-high walls) arms emanating from a common central platform $(6 \mathrm{~cm} \times 6 \mathrm{~cm})$ and was placed $60 \mathrm{~cm}$ above the ground. At the start, animals were placed at the junction of the open and closed arms with the head facing the closed arms. The behavioral test was performed in the dark phase under dim-light conditions, and exploratory behavior was videotaped with a high-speed camera (25 frames per second) (GigE, Basler AG, Ahrensburg, Germany) for 5 min. EthoVision XT9 software (Noldus, Wageningen, Netherlands) was used to track the activity patterns. The times spent in the open and closed arms were examined as a time ratio (RT). The RT is the time spent in the open arms (TO)/total time spent in both closed (TC) and open arms (TO): $\mathrm{RT}=\mathrm{TO} /(\mathrm{TO}+\mathrm{TC})$. In addition, the frequency of transition between the arms, the total distance traveled, and the velocity were measured. Between each animal, the maze was cleaned with $70 \%$ ethanol and dried before testing the next animal.

\section{Resident-Intruder Paradigm}

The resident-intruder paradigm was performed in order to assess territorial aggression on five consecutive days. The experiment started on day 13 and lasted until day 17, and testing took place in the housing cages of BALB/cJ mice that had not been cleaned after arrival. On each testing day, an unfamiliar C57BL/6J intruder mouse was encountered, which was randomly assigned to a resident for each interaction. All animals, both resident and intruder, were tested once a day. The housing cage of the resident was used as the interaction area, which was placed in front of an infrared high-speed camera (25 frames per second) (GigE, Basler AG, Ahrensburg, Germany). A transparent Plexiglas screen was placed in the middle of the cage, to prevent direct interaction between animals but to enable visual, auditory, and olfactory perception. The intruder mouse was placed at the other side of the plastic screen for a period of $5 \mathrm{~min}$. Hereafter, the screen was removed, and the interaction was videotaped for $5 \mathrm{~min}$. After the test, the intruder was removed from the cage, and both animals were weighed and checked for wounds. Treatment with vehicle or MPH was given 20 min prior testing, but only on the first and last days of the resident-intruder paradigm. The frequency 
of attacks and bites and the latency to the first attack were analyzed manually for all interaction days. A broader range of the behavioral repertoire (e.g., bites, attacks, lateral threats, and tail rattles as described by 34,35 ) was scored on the MPH-treated days (day 1 and day 5). An attack latency of $300 \mathrm{~s}$ was taken in case no attack occurred within the 5-min interaction window.

\section{Mixed-Cue Fear Conditioning}

Fear conditioning was performed in Bussey-Saksida Mouse Touch Screen Chambers (Campden Instruments Ltd, Loughborough, United Kingdom) on days 20-22. An aversion stimulus dual shocker (Kinder Scientific, Poway, California, United States) connected to the chambers was used to provide manual shocks to the animals via a grid floor. On the first day, in the "cue conditioning" phase, animals were placed individually into the fear-conditioning arena and were habituated for $3 \mathrm{~min}$. After habituation, the cue conditioning started with an acoustic conditioned stimulus (CS) $(2 \mathrm{kHz})$, which lasted for $30 \mathrm{~s}$, which was accompanied by an unconditioned stimulus (US) of electric foot shock $(0.7 \mathrm{~mA})$ during the last $2 \mathrm{~s}$ of the CS. This cue conditioning was repeated three times with an inter-trial interval of $95 \mathrm{~s}$. On the second day, in the "cue extinction" phase, animals were injected with either MPH or vehicle 20 min prior to the test. Mice were placed in the same box as the day before and were again habituated for $3 \mathrm{~min}$ before the trials started. Fifteen trials were given, exclusive of the CS, with a duration of $30 \mathrm{~s}$ and an inter-trial interval of $10 \mathrm{~s}$ between them. No US stimulus was given in the cue extinction. On the third day, the protocol of the second day was repeated, only without drug administration. Between and after each test, the fear-conditioning area was cleaned with $70 \%$ ethanol. Freezing during the 15 cue extinction trials was quantified manually by Observer XT software (Noldus, Wageningen, Netherlands). As an additional measure, the amount of beam breaks during the habituation on all 3 days and the beam breaks during the 15 cue extinction trials (on day 2 and day 3) were analyzed with ABET II Software for Touch Screens (Lafayette Instruments Company, Lafayette, Indiana, USA).

\section{Circular Corridor}

Locomotor activity of the animals after treatment with $\mathrm{MPH}$ or vehicle ( $n=4$ per group) was measured in the circular corridor test. In order to keep testing within the first hours after darkness, only three animals were tested per morning session, and animals were randomly assigned to the testing days on either day $27,28,30$, or 36 . This setup consists of two Plexiglas cylinders; the outer cylinder had a diameter of $24 \mathrm{~cm}$ and was $20 \mathrm{~cm}$ in height, and the inner cylinder had a diameter of $11.5 \mathrm{~cm}$ and was $15 \mathrm{~cm}$ in height, which creates a corridor of $6.25 \mathrm{~cm}$ in width. Each animal was free to explore the circular corridor for $60 \mathrm{~min}$, without prior habituation, $20 \mathrm{~min}$ after the injection. The exploration pattern was recorded with a highspeed infrared camera (25 frames per second) (GigE, Basler AG, Ahrensburg, Germany) placed above the setup. After each $\mathrm{BALB} / \mathrm{cJ}$, the setup was cleaned with $70 \%$ ethanol. EthoVision XT9 software (Noldus, Wageningen, Netherlands) was used to analyze the distance that was traveled within the total testing period and within the first $15 \mathrm{~min}$, which was thought to be the most effective period of $\mathrm{MPH}$, since the DA increase by $\mathrm{MPH}$ decreases $40 \mathrm{~min}$ after the i.p. injection (32).

\section{Data Analysis and Statistics}

An a priori power analysis was conducted with an expected effect size of 0.60 , an $\alpha$ of 0.05 , and $\beta$ of 0.80 , which predicted that a minimum of 10 mice per condition was required. Based on prior experience, we predicted that approximately $20 \%$ of the animals had to be excluded from further analysis due to behavioral reasons or other complications caused by the injections. For these reasons, we used 12 animals per treatment group. All data were analyzed using IBM SPSS Statistics (version 24.0, Chicago, USA). Normality of the data was assessed with the KolmogorovSmirnov test. Data that were normally distributed were analyzed by paired Student $t$-tests or (repeated measures) analysis of variance (ANOVA), followed by Bonferroni corrected post hoc t-tests. Nonparametric Mann-Whitney tests, Wilcoxon signed rank tests, and Kruskal-Wallis tests were used for non-normally distributed data. The Dunn post hoc method was performed to correct for multiple nonparametric comparisons. Relationships within the data (elevated plus maze: ratio open/closed arms; open field: number of center visits; resident-intruder test: number of bites, number of attacks; social interaction test: time spent near social cylinder; mixed-cue fear-conditioning test: time spent freezing; total number of beam breaks; and circular corridor: total distance travelled) were assessed using Pearson correlations. Outliers in the data were excluded by Tukey's method, namely, when diverging more than $1.5 \times$ interquartile range different from the median (36). All statistical tests were two-sided with a significance level of $p<0.05$, indicating statistical significance. GraphPad PRISM (version 5.03, GraphPad Software Inc., La Jolla, US) software was used to output data into images.

\section{RESULTS}

\section{MPH Suppresses Anxiety-Related Behavior}

The open-field test and the elevated plus maze were performed in order to assess the effect of MPH on anxiety and explorative behavior in BALB/cJ mice. Similar to a previous report, BALB/cJ mice treated with vehicle exhibit a long period of immobility in the starting position, which was the center of the field (30). Both 3 and $10 \mathrm{mg} / \mathrm{kg}$ i.p. MPH increased the frequency of visits to the center $\left(H_{2}=15.121, p=0.001\right.$, VEH vs MPH3: $p=0.016$; VEH vs MPH10: $p<0.001$ ) (Figures 2A, B). Additionally, the distance traveled and the velocity increased significantly compared to those in vehicle-treated animals (Figures 2C, D).

Similar findings were observed in the elevated plus maze, where, as shown in Figures 3A, B, a significant difference was found in the ratio between the duration spent in the open and closed arms of the maze between vehicle- and MPH-treated groups. After administration with either dosage of $\mathrm{MPH}$, mice spent significantly more time in the open arms compared to mice treated with vehicle $\left(H_{2}=0.407, p=0.816\right.$; VEH vs MPH3: $p=$ 0.038; VEH vs MPH10: $p=0.040 ; \mathrm{MPH} 3$ vs MPH10: $p=$ n.s.). 


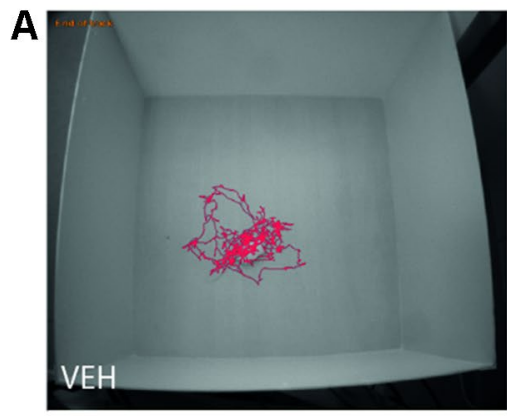

B

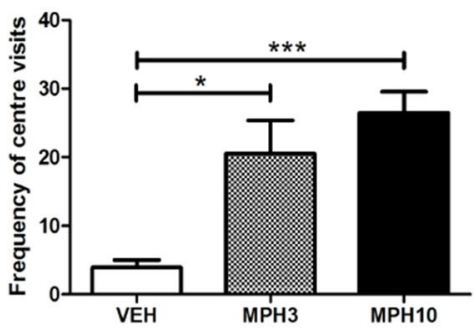

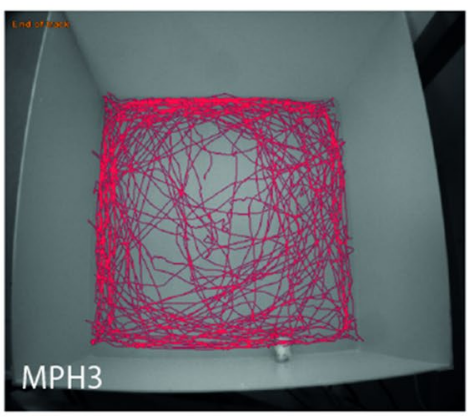

C

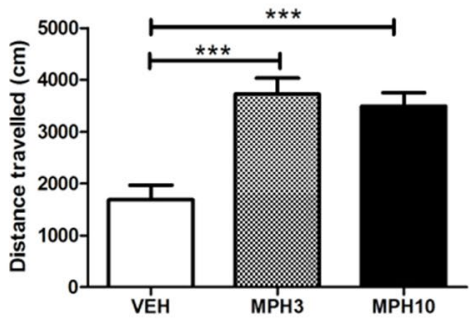

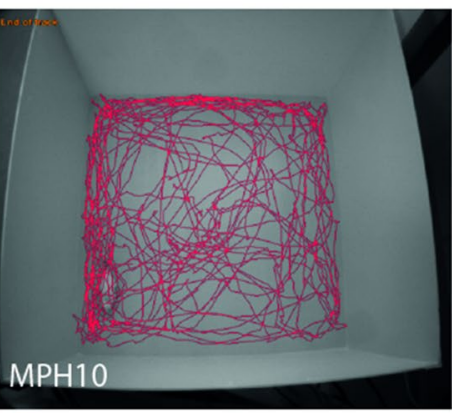

D

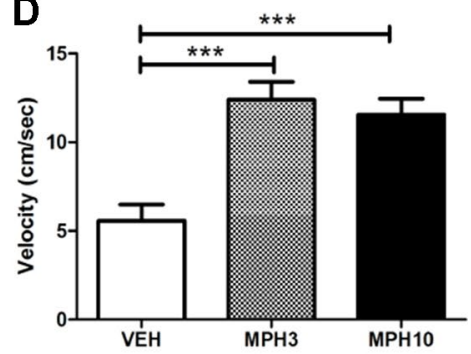

FIGURE 2 | Open-field experiment. (A) Typical representations of exploratory patterns of BALB/cJ mice in open field. While the vehicle remains most of the time at the start position, the methylphenidate (MPH)-treated animals explore the whole field, and (B) MPH increased the number of center visits and (C) the distance traveled as well as (D) the velocity. Abbreviations: VEH, vehicle; MPH3, 3 mg/kg i.p. methylphenidate; MPH10, 10 mg/kg i.p. methylphenidate. N = 12 per group, ${ }^{*} p<0.05,{ }^{* \star *} p<0.001$

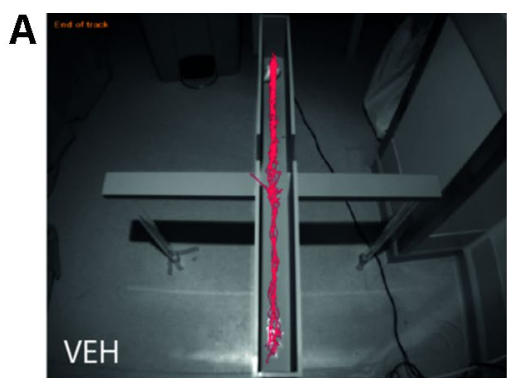

B

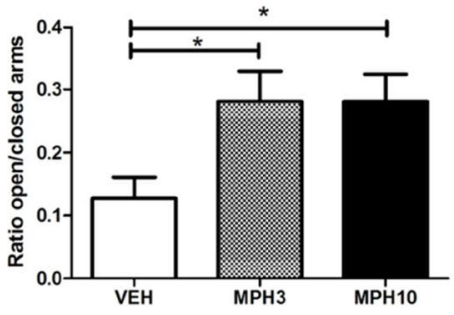

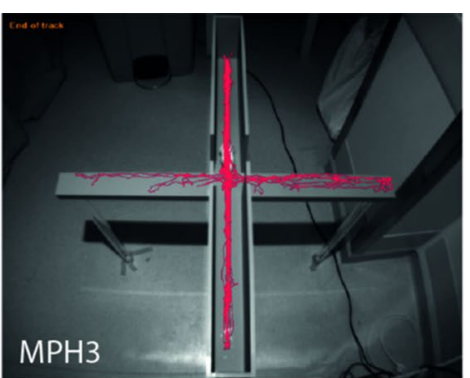

C

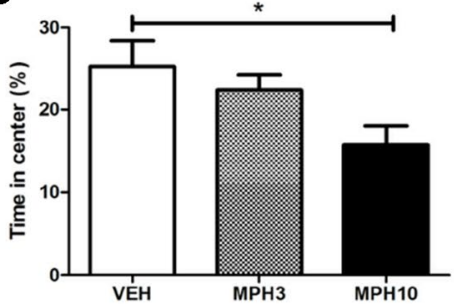

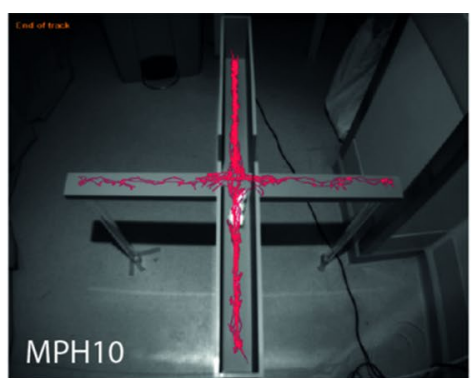

D

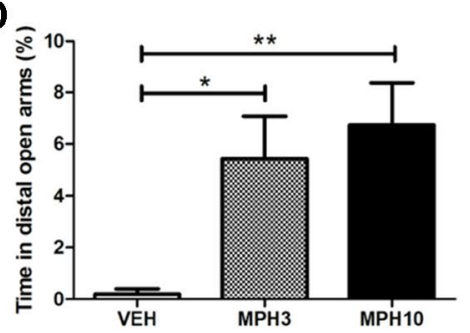

FIGURE 3 | Elevated plus maze. (A) Typical representations of exploratory patterns of BALB/cJ mice on the elevated plus maze. While the vehicle remains in the closed arms for most of the time, the methylphenidate (MPH)-treated animals explore the open arms. (B) MPH increased the time spent on the open arms as a ratio of the time spent on both the closed and open arms. (C) The vehicle-treated animals stay in the center of the maze. (D) The MPH-treated animals spent more time in the distal parts of the open arms. Abbreviations: $\mathrm{VEH}$, vehicle; MPH3, $3 \mathrm{mg} / \mathrm{kg}$ i.p. methylphenidate; MPH10, $10 \mathrm{mg} / \mathrm{kg}$ i.p. methylphenidate. $\mathrm{N}=12$ per group, ${ }^{*} p<0.05,{ }^{* *} p<0.01$

$\mathrm{BALB} / \mathrm{cJ}$ mice treated with vehicle spent more time on the central platform of the maze compared to mice treated with $\mathrm{MPH}\left(F_{(2,33)}=4.4506, p=0.019\right.$; VEH vs MPH3: $p=$ n.s.; VEH vs MPH10: $p=0.015$, MPH3 vs MPH10: $p=$ n.s.) (Figure 3).
To examine anxiolytic effects of MPH, the duration spent in the distal open arms was examined, as a gauge for their exploratory/ anxiety behavior. MPH significantly increased the time spent in the distal open arms of the elevated plus maze, in both treatment 
groups compared to the vehicle group $\left(H_{2}=10.619, p=0.005\right.$; VEH vs MPH3: $p=0.026$; VEH vs MPH10: $p=0.002$, Figure 3). Additionally, the velocity and distance moved were significantly different between all three treatment groups. Compared to vehicle, administration of $\mathrm{MPH}$ increased the velocity $\left[F_{(2,33)}=\right.$ $10.12, p \leq 0.001$; VEH vs MPH3: $p=0.037$; VEH vs MPH10: $p \leq$ 0.001; MPH3 vs MPH10: $p=$ n.s., Figure S2A] and the distance traveled in a dose-dependent manner $\left[F_{(2,33)}=10.209, p \leq 0.001\right.$; VEH vs MPH3: $p=0.040$; VEH vs MPH10: $p \leq 0.001$; MPH3 vs MPH10: $p=$ n.s., Figure S2B). Previous studies showed increased locomotor activity by administration of MPH (37). To examine the possibility that the increased distance traveled, in both the open-field test and the elevated plus maze, was the result of hyperactivity caused by MPH administration, a circular corridor test was performed. Locomotor activity was measured during the first $15 \mathrm{~min}$ as a measure of treatment reactivity to the novel environment. A significant difference has been found in the traveled distance between the $10 \mathrm{mg} / \mathrm{kg} \mathrm{MPH}$ and vehicle treatment groups $\left[F_{(2,8)}=5.519, p=0.031\right.$; VEH vs MPH3: $p=$ n.s.; VEH vs MPH10: $p=0.040$; MPH3 vs MPH10: $p=$ n.s., Figure S3). While the $3 \mathrm{mg} / \mathrm{kg} \mathrm{MPH}$-treated group did not differ in explorative behavior compared with the vehicle group, we cannot completely rule out a hyperactivity effect on the anxiety measures given the limited number of observations.

\section{Improved Fear-Extinction Learning by MPH}

Extinction of conditioned fear was based on the reduction in the response according to the repetitive presentation of a tone (CS) in the absence of the foot shock (US). We assessed the effect of MPH on mixed-cue fear conditioning in BALB/cJ mice. Drug treatment was given prior to fear extinction learning as depicted in Figure 4. During extinction learning, administration of $\mathrm{MPH}$ decreased the freezing time in mice treated with 3 and
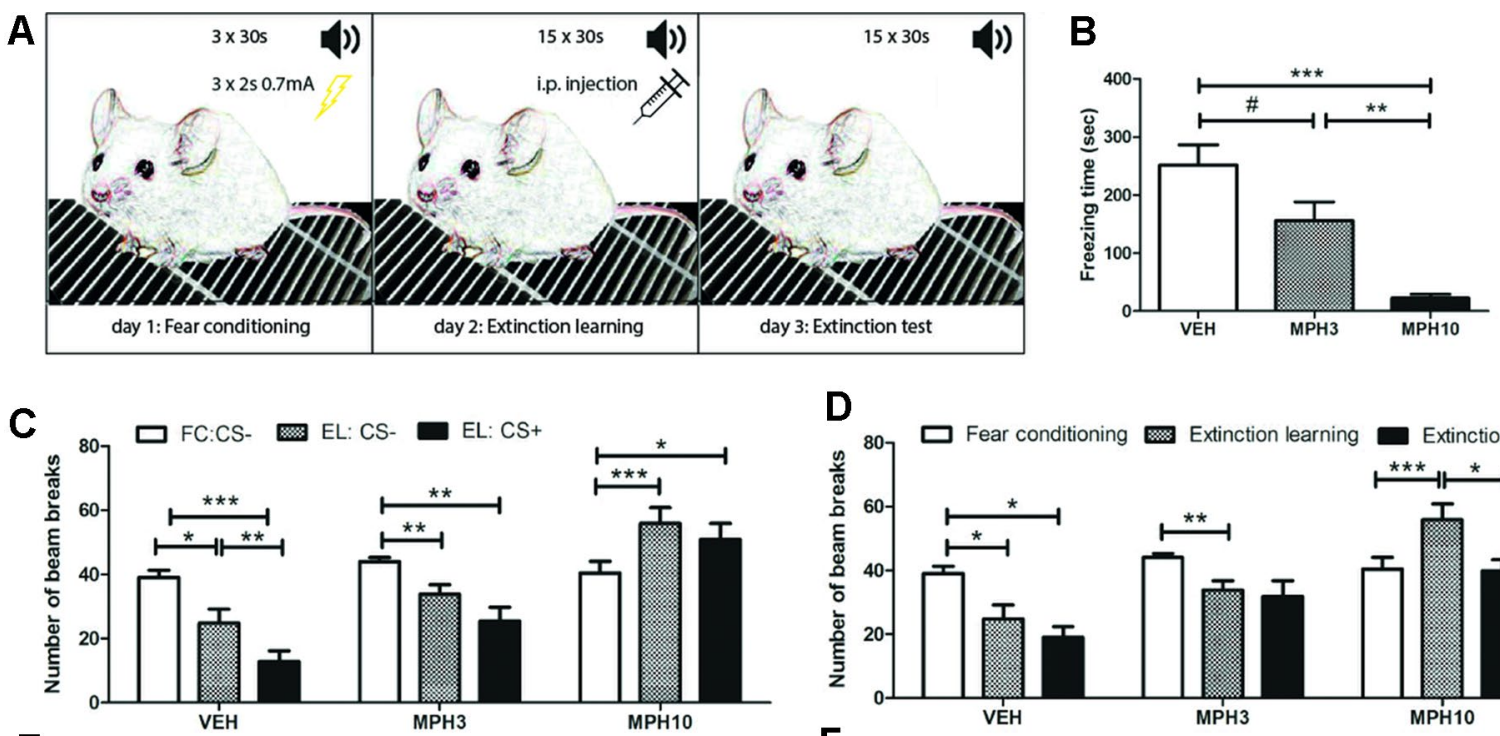

E
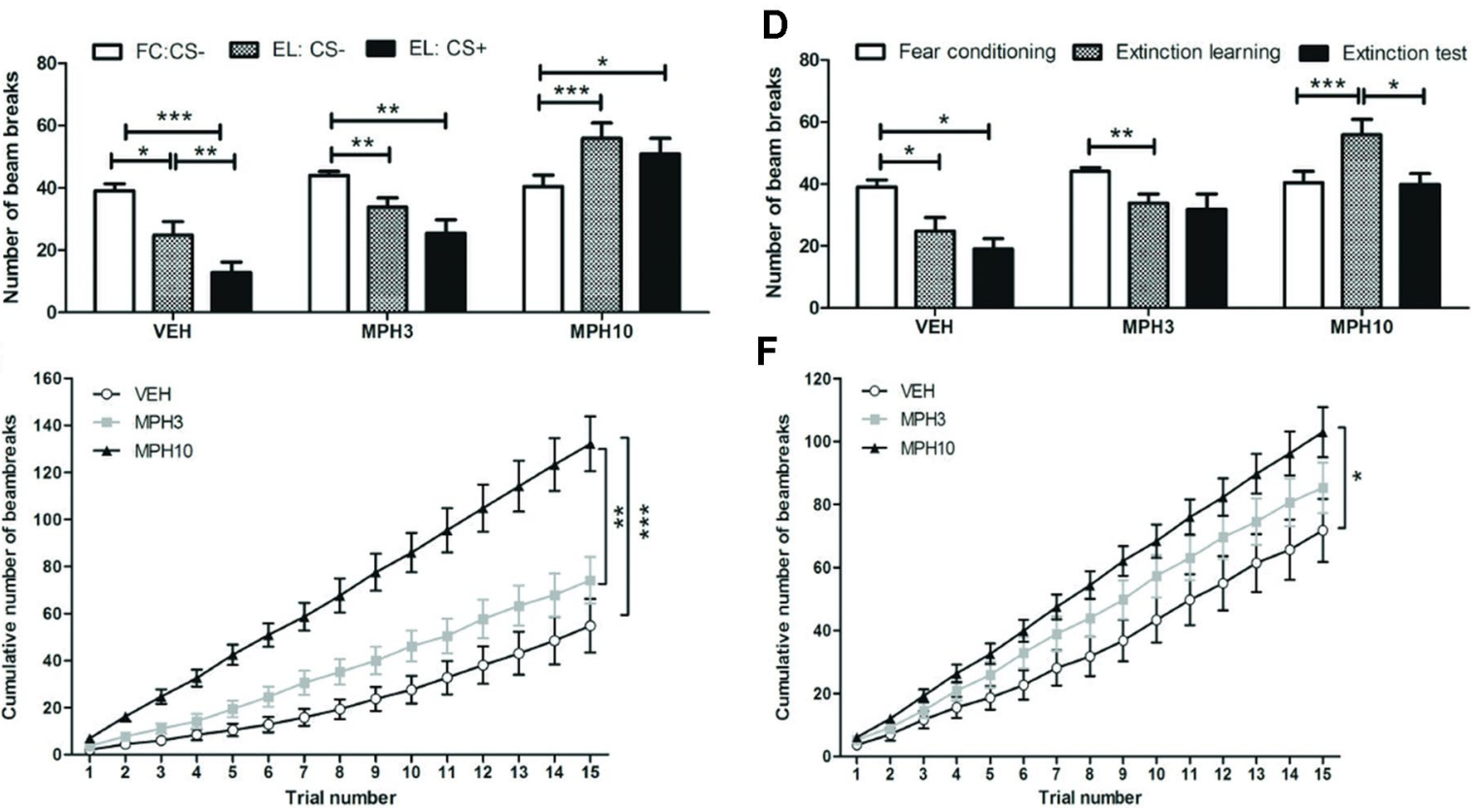

$\mathbf{F}$

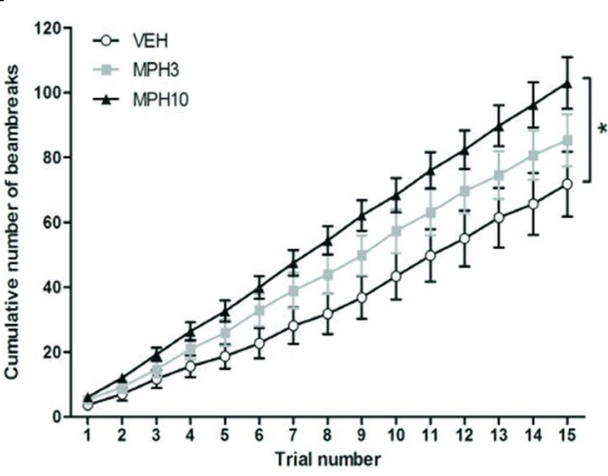

FIGURE 4 | Mixed-cue fear-conditioning test. (A) Overview of the test procedure. On the first day (fear conditioning), animals received three sessions of $30 \mathrm{~s}$ of an auditory cue, of which the last $2 \mathrm{~s}$ was paired with $0.7 \mathrm{~mA}$ foot shock. On day 2, the extinction learning, the auditory cue was presented during 15 trials of $30 \mathrm{~s}$ without the shock. Animals were injected with either MPH or vehicle 20 min before this task. On the third day, the extinction test, the auditory cue was presented during 15 trials of $30 \mathrm{~s}$ each. (B) The time spent freezing on the extinction learning day decreased with the methylphenidate (MPH) dose. (C) The number of beam breaks is presented during the habituation phases (CS-) of the fear conditioning (FC) and extinction learning (EL) and during the presentation of the auditory cue (CS+) during EL. (D) The number of beam breaks of the habituation phases is compared between all three testing days. (E) The graph represents the cumulative number of beam breaks on the extinction learning day and (F) extinction test day. Abbreviations: FC, fear conditioning; EL, extinction learning, i.p., intraperitoneal; CS-, conditioned stimulus absent; CS+, conditioned stimulus present; VEH, vehicle; MPH3, 3 mg/kg i.p. MPH; MPH10, 10 mg/kg i.p. MPH. N $=12$ per group, ${ }^{*} p<0.010 ;{ }^{*} p<0.05 ;{ }^{* \star} p<0.01 ;{ }^{* \star} p<0.001$. 
$10 \mathrm{mg} / \mathrm{kg} \mathrm{MPH}$ compared to vehicle $\left[F_{(2,33)}=17.275, p \leq 0.001\right.$; VEH vs MPH3: $p=0.059$; VEH vs MPH10: $p=<0.001$; MPH3 vs MPH10: $p=0.005$, Figure 4]. As an additional measure of activity, we measured the number of infrared beams, located at the front and the back of the chamber, that were crossed by the animals. No significant differences were found in the activity during the habituation phase before conditioning between the treatment groups, indicating no prior group differences in anxiety or locomotor activity (Figure S4). During extinction learning, a significant difference in baseline locomotor activity was found between the highest dose of $\mathrm{MPH}$ and the other groups $\left[F_{(2,33)}=14.41, p \leq 0.0001\right.$; VEH vs MPH3: $p=0.866$; VEH vs MPH10: $p \leq 0.0001$; MPH3 vs MPH10: $p=0.001$ ], in which the animals treated with $10 \mathrm{mg} / \mathrm{kg} \mathrm{MPH}$ demonstrated an increased number of beam breaks (Figures 4 and S4). The vehicle group $\left(t_{24}=2.934, p=0.014\right)$ and the $3 \mathrm{mg} / \mathrm{kg} \mathrm{MPH}$ group $\left(t_{18}=3.624, p=0.007\right)$ showed a reduction in the number of beam breaks when comparing activity during the habituation phase of the conditioning and extinction phase, while in the 10 $\mathrm{mg} / \mathrm{kg} \mathrm{MPH}$ group, an increased number in bream breaks was found $\left(t_{24}=-4.983, p \leq 0.001\right)$ (Figures 4 and S4). In addition, during extinction learning, only the vehicle group showed significantly reduced activity when the CS was presented $\left(t_{24}=\right.$ 3.970, $p=0.002$ ), as is shown in Figure 4. A long-lasting effect of the fear conditioning was seen during the extinction test in the vehicle-treated animals, in which the number of beam breaks was still significantly reduced when compared to the habituation phase of the conditioning day $\left(t_{24}=2.382, p=0.036\right)$; this was not observed in the MPH-treated mice (Figure 4). In addition, administration of $10 \mathrm{mg} / \mathrm{kg}$ of $\mathrm{MPH}$ increased the total number of beam breaks over $15 \mathrm{CS}+$ sessions significantly during both extinction learning $\left[F_{(2,33)}=16.880, p \leq 0.001\right.$; VEH vs MPH3: $p=$ n.s.; VEH vs MPH10: $p \leq 0.001$; MPH3 vs MPH10: $p=0.001$, Figure 4] and the extinction test $\left[F_{(2,33)}=3.702, p=0.035 ; \mathrm{VEH}\right.$ vs MPH3: $p=$ n.s.; VEH vs MPH10: $p=0.031$, MPH3 vs MPH10: $p=$ n.s., Figure 4] compared to vehicle, indicating a long-lasting effect of MPH on fear extinction.

\section{MPH Affects Social Interest Dose-Dependently}

Previous observations have indicated decreased social interaction in $\mathrm{BALB} / \mathrm{cJ}$ compared to $\mathrm{C} 57 \mathrm{BL} / 6 \mathrm{~J}$ (28). Therefore, we have investigated whether MPH has an effect on social behavior using the social cognition test and the resident-intruder paradigm. The social cognition test showed that all groups have increased interest for the zone without the unfamiliar animal, the so-called non-social zone (VEH $t_{11}=-2.258, p=0.045$; $\mathrm{MPH} 3 t_{10}=-5.561$, $p<0.001$; MPH10 $t_{11}=-1.168, p=0.267$; Figure 5). However, if we focus on the time that the animals have investigated the cylinder itself, there is no difference between the time spent near the social and non-social cylinders for the vehicle-treated animals $\left(t_{11}=0.479, p=0.641\right)$ and animals treated with $10 \mathrm{mg} /$ $\mathrm{kg} \mathrm{MPH}\left(t_{10}=0.340, p=0.741\right)$. In contrast, animals treated with $3 \mathrm{mg} / \mathrm{kg} \mathrm{MPH}$ have a preference for the non-social cylinder $\left(t_{9}=-2.722, p=0.024\right)$ (Figure 5). In addition, the vehicletreated animals spend more time per interaction with the social

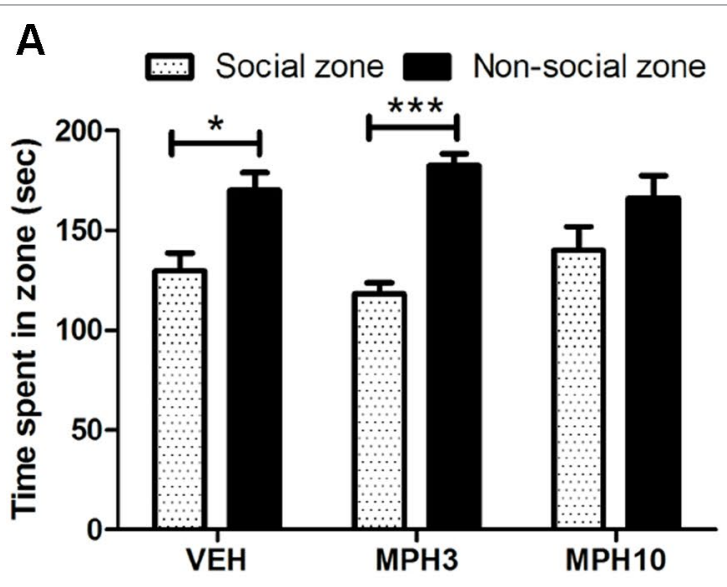

B

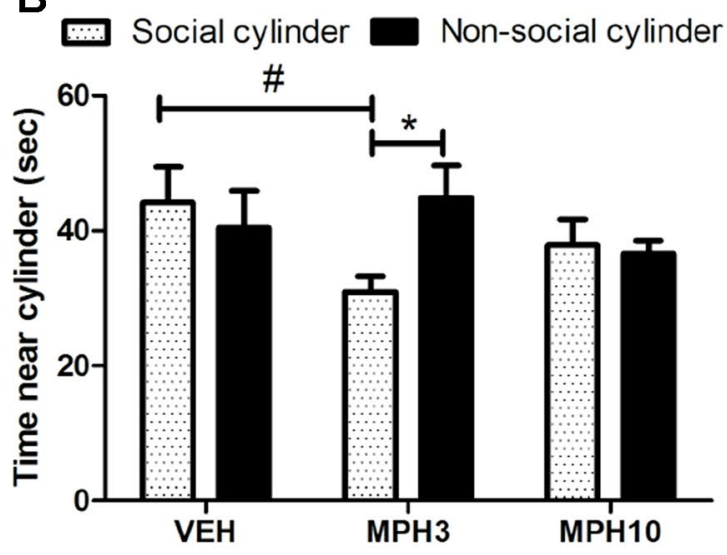

C

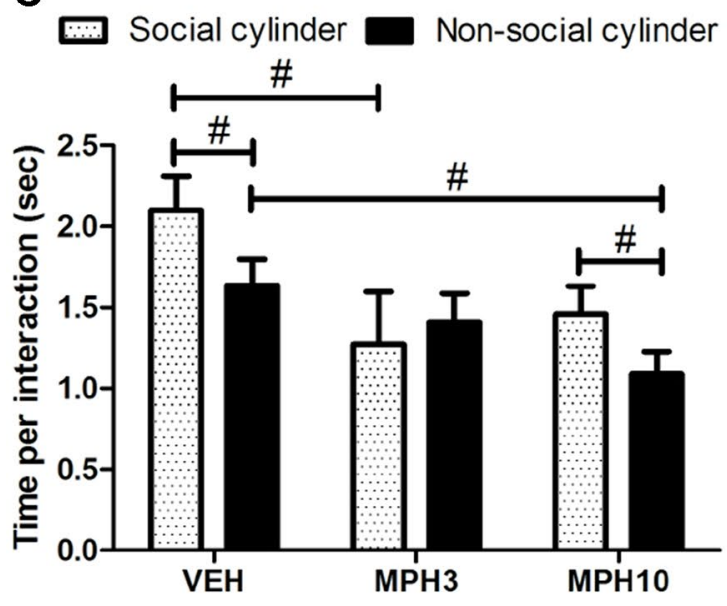

FIGURE 5 | Social interaction test. (A) BALB/cJ mice treated with vehicle and $3 \mathrm{mg} / \mathrm{kg}$ i.p. methylphenidate (MPH) show a preference for the nonsocial zone. (B) The dose of $3 \mathrm{mg} / \mathrm{kg}$ i.p. MPH increased the preference for the non-social cylinder in comparison to the social cylinder and the vehicletreated mice. (C) Both the vehicle-treated and $10 \mathrm{mg} / \mathrm{kg}$ i.p. MPH-treated mice show a longer interaction time with the social cylinder, while this is not the case for the $3 \mathrm{mg} / \mathrm{kg}$ group. Abbreviations: VEH, vehicle; MPH3, $3 \mathrm{mg} /$ kg i.p. MPH; MPH10, 10 mg/kg i.p. MPH. $\mathrm{N}=12$ per group, ${ }^{\#} p<0.10$; ${ }^{*} p<$ $0.05 ;{ }^{* \star \star} \mathrm{p}<0.001$ 
cylinder in comparison to the non-social cylinder (Figure 5). In addition, it was found that the time per interaction with the social cylinder was also decreased for the animals that received $\mathrm{MPH}$ in contrast to animals that received vehicle $\left[F_{(2,33)}=3.189\right.$, $p=0.055 ; \mathrm{VEH}$ vs MPH3: $p=0.065$; VEH vs MPH10: $p=0.214$, Figure 5]. While both the vehicle group and the $10 \mathrm{mg} / \mathrm{kg} \mathrm{MPH}$ group spent a longer time per interaction with the social cylinder in comparison to the non-social cylinder, this was not found in the mice treated with $3 \mathrm{mg} / \mathrm{kg} \mathrm{MPH}$ (Figure 5).

\section{MPH Dose-Dependently Produces Opposing Effects on Aggression}

The resident-intruder paradigm was performed to assess aggression in BALB/cJ mice treated with $\mathrm{MPH}$ or vehicle. The test was performed for five successive days, in which BALB/cJ mice were only treated the first and last days of the test with MPH or vehicle 20 min prior testing (see Figure 1). As displayed in Figure 6, no significant difference was found between the attack latencies of $\mathrm{BALB} / \mathrm{cJ}$ of the different treatment groups. For all groups, attack latencies decreased on the second day of the resident-intruder paradigm compared to the first day, which is considered as normal behavioral response, and aggression is stabilized after 3 days (35). Although there was no significant difference between groups when each day was compared separately, it was found that the average attack latency of the last 3 days was longer for the $3 \mathrm{mg} / \mathrm{kg} \mathrm{MPH}$-treated animals $\left(\mathrm{H}_{2}=\right.$ 6.273, $p=0.043$ ) (Figure 6B). Figure 6C shows the number of bites on both injection days (day 1 and day 5). Whereas we see an increase in the number of bites from days 1 to 5 in the vehicletreated animals $\left(t_{18}=-3.091, p=0.013\right)$, the level of aggression stays at the level of day 1 for the $3 \mathrm{mg} / \mathrm{kg}\left(t_{16}=0.555, p=0.594\right)$ and $10 \mathrm{mg} / \mathrm{kg}\left(t_{22}=0.263, p=0.798\right) \mathrm{MPH}$-treated animals. An increased number of bites is observed in the $10 \mathrm{mg} / \mathrm{kg} \mathrm{MPH}$ on day $1\left[F_{(2,30)}=6.789, p=0.004 ; \mathrm{VEH}\right.$ vs MPH10: $p=0.006$; MPH3 vs MPH10: $p=0.024)$ in comparison to the other groups (Figure 6C). On day 5, both the vehicle-treated animals and the $10 \mathrm{mg} / \mathrm{kg}$ MPH-treated animals have a higher number of bites in comparison to the group treated with $3 \mathrm{mg} / \mathrm{kg} \mathrm{MPH}\left(F_{(2,31)}=\right.$ 3.474, $p=0.044$; VEH vs MPH3: $p=0.117$; MPH3 vs MPH10: $p=$ 0.061) (Figure 6C). A similar pattern is found for the number of attacks, as is shown in Figure 6D. This number of attacks increases for the vehicle group $\left(t_{20}=-2.691, p=0.023\right)$, whereas it remains at the level of day 1 for both the $10 \mathrm{mg} / \mathrm{kg} \mathrm{MPH}$ (high number of attacks) and the $3 \mathrm{mg} / \mathrm{kg} \mathrm{MPH}$ (low number of attacks). Interestingly, in the $3 \mathrm{mg} / \mathrm{kg} \mathrm{MPH}$ group, the number of threats reduced over time $\left(Z_{24}=-2.491, p=0.013\right)$, while the number of threats increased for the vehicle-treated animals $\left(Z_{24}=-2.357, p=0.018\right)$ (Figure 6E). On day 5, the number of threats in the $3 \mathrm{mg} / \mathrm{kg} \mathrm{MPH}$ group is significantly lower $\left(\mathrm{H}_{2}=\right.$ $14.650, p=0.001)$ than that in the vehicle group $(p=0.002)$ and the $10 \mathrm{mg} / \mathrm{kg} \mathrm{MPH}$ group ( $p=0.008$ ) on day 5 . At the first day of the resident-intruder test, there is no significant difference between the number of threats observed in all three groups, which indicates that the elevated level of aggression seen in the $10 \mathrm{mg} / \mathrm{kg} \mathrm{MPH}$ group is accompanied by less threat behavior.

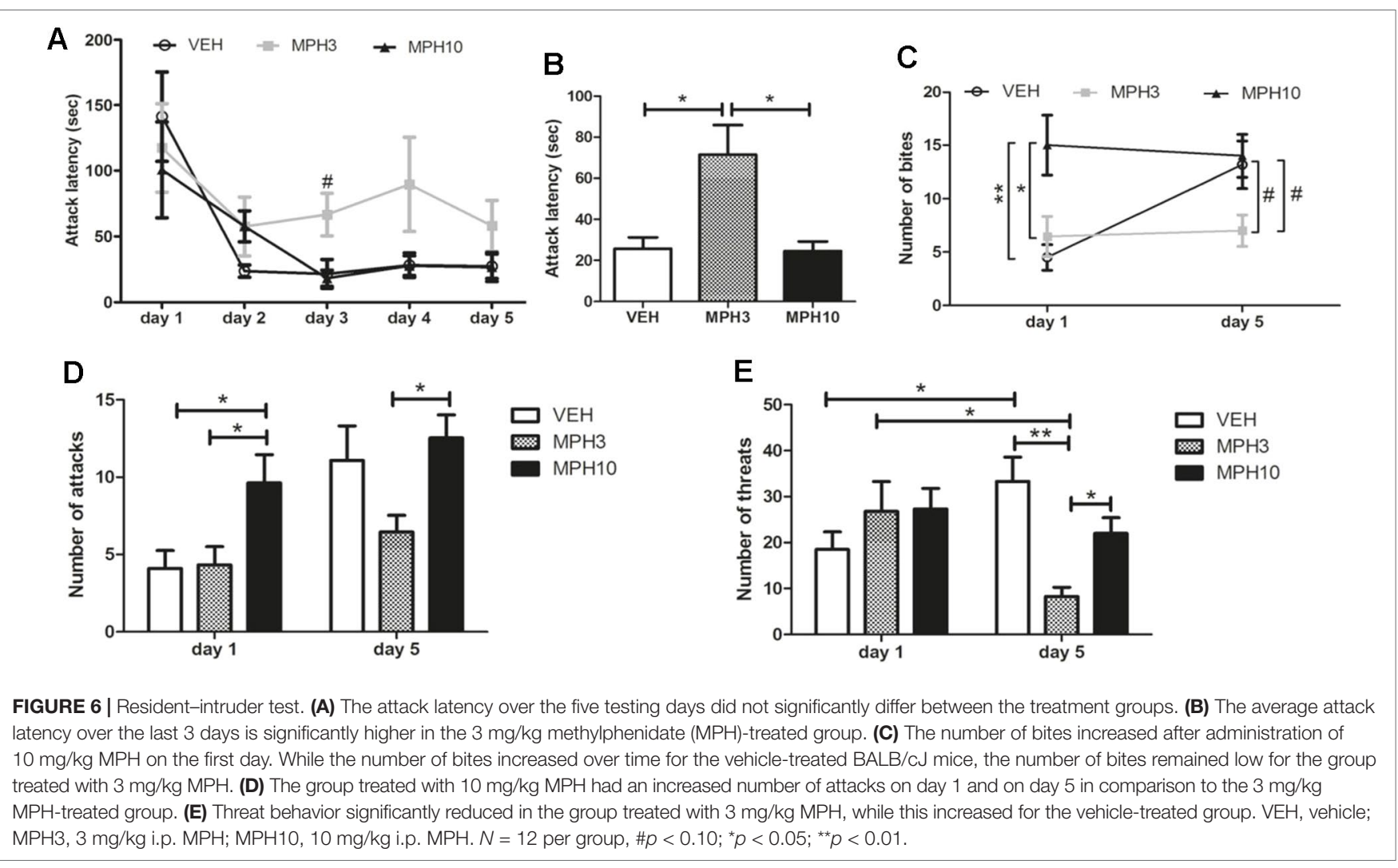




\section{DISCUSSION}

The current study assessed the effect of MPH on anxiety, fear extinction, and aggressive behavior in the BALB/cJ mouse, as a model for these behavioral characteristics in relation to ADHD and $\mathrm{CD}$. Our previous research has shown that BALB/cJ mice exhibit increased aggression, increased anxiety, and antisocial behavior (28-30), which makes this mouse strain an ideal model to answer the following questions: (1) Does MPH affect anxiety and fear extinction? (2) Does MPH affect social behavior and aggression, and if so, is this dose dependent? A clear overview of the behavioral outcome can be found in Table $\mathbf{1}$.

\section{Anxiolytic and Fear Extinction-Improving Effects of MPH in a Dose-Dependent Manner}

In BALB/cJ mice, treatment with both the 3 and $10 \mathrm{mg} / \mathrm{kg}$ dose had an anxiolytic action in the open field and in the elevated plus maze. This may reflect changes in state anxiety. Opposite results were obtained in a study in $\mathrm{C} 57 \mathrm{BL} / 6 \mathrm{~J}$ mice, which became more anxious after MPH treatment $(38,39)$. C57BL/6J mice are in general less anxious than $\mathrm{BALB} / \mathrm{cJ}$ mice (40), so this result may indicate that MPH can have different effects in different (high and low anxiety) rodent strains, which may be a consequence of differential drug-genetic background effects. Administration of $2.7 \mathrm{mg} / \mathrm{kg} \mathrm{MPH}$ i.p. to Wistar rats exposed to unpredictable chronic stress decreased the immobility compared to salineinjected rats after fear conditioning (41). Similarly, we found that administration of 3 and $10 \mathrm{mg} / \mathrm{kg}$ i.p. MPH reduced immobility upon the US and improved extinction, measured by the number of beam breaks and the time spent freezing. Improved extinction learning was even visible $24 \mathrm{~h}$ after the actual injection of $10 \mathrm{mg} /$ $\mathrm{kg}$ i.p. was given (extinction test phase), indicating a long-lasting effect of MPH on fear retrieval, which suggest changes in trait anxiety and fear processing. In agreement with our findings, a study in C57BL/ 6 mice showed that administration of MPH before or immediately following extinction of contextual fear enhances extinction retention, with also long-lasting effect of the $10 \mathrm{mg} / \mathrm{kg}$ i.p. dose (27). Still, it needs to be considered that these long-lasting effects of MPH may also be due to changes related to the circadian rhythm of the subjects. We have repeatedly administered MPH to the animals, and to prevent accumulation of the drug, we scheduled a minimum of 3 days between injections. However, we cannot be certain that the effect of the drug from preceding administration did not induce some longer-lasting biological change, for example, gene expression that may affect subsequent tests.

It was found that administration of MPH after the extinction learning was effective, indicating that the timing of the injection has a large influence on the behavioral outcome $(27,42)$. Given the highly anxious phenotype of BALB/cJ mice (30), we could argue that $\mathrm{MPH}$ reduced both the state and trait anxiety during fear extinction and prevented fear retrieval. Since we observed long-lasting effects of the $10 \mathrm{mg} / \mathrm{kg}$ i.p. dose, this may indicate that the initial association between the CS and US has been diminished and may reflect an alteration of the underlying trait. The clinical implications of MPH utility on fear processing need to be more fully explored but may involve complex interactions with genotype and environmental triggers, so caution should be taken in extrapolating the ability of MPH to reduce immobility/ freezing and improve fear extinction processing in this model. Moreover, while reducing anxiety may play a part of the antiaggressive response of low-dose $\mathrm{MPH}$, it is not the only possible explanation, especially as both doses reduce anxiety but only the lower dose is anti-aggressive. The role of anxiety in regulating aggression in BALB/cJ mice is worth following up in directed studies. We have previously published that GABAergic inhibition is diminished in the anterior cingulate cortex (ACC) of these mice (relative to BALB/cByJ mice) (30), a brain region also implicated in anxiety, so anti-anxiety effects of $\mathrm{MPH}$ in this model should not be fully discounted as it may reduce defensive behavior. Investigation of the effects of MPH on GABAergic transmission in the ACC of BALB/c substrains would be useful to ascertain a mechanism of action for the behavioral effects reported here.

We observed that MPH increased locomotor activity in both the open field and elevated plus maze. While there was no difference between the distance traveled between the 3 and $10 \mathrm{mg} / \mathrm{kg}$ i.p. MPH-treated BALB/cJ mice in the open field, a dose-dependent effect was observed in the elevated plus maze. Additional testing to clarify any locomotion-related effect demonstrated that in the circular corridor paradigm, only the higher $10 \mathrm{mg} / \mathrm{kg}$ dose of MPH was associated with hyperactivity in BALB/cJ mice. While no difference was observed between the vehicle-treated animals and those administered $3 \mathrm{mg} / \mathrm{kg} \mathrm{MPH}$, we cannot completely rule out an effect caused by hyperactivity in the animals treated with the $3 \mathrm{mg} / \mathrm{kg} \mathrm{MPH}$ because of the low sample size used in this paradigm. Previous studies that administered MPH to rodents also showed a dose-responsedependent increased locomotor activity in which the effect was clearest in the high-dose group $(25,43,44)$. However, in our experimental setting, it needs to be considered that the fearconditioning test, a week prior to the corridor test, may have influenced the behavioral outcome in the test.

While it is clear that both the low and high doses of MPH increase motor activity in the elevated plus maze, this is not correlated with the anxiety metrics in the elevated plus maze, nor was this effect observed in the open-field test. The correct interpretation of any MPH-induced hyperactivity is important

TABLE 1 | Behavioral effects of different dosages of methylphenidate in BALB/CJ mice.

\begin{tabular}{lcccc}
\hline Drug & \multicolumn{3}{c}{ Behavior } \\
\cline { 2 - 4 } Methylphenidate dose & Locomotion & Anxiety & Social interest & Fear extinction \\
\hline Low $(3 \mathrm{mg} / \mathrm{kg})$ & - & $\downarrow$ & $\downarrow$ & Aggression \\
High $(10 \mathrm{mg} / \mathrm{kg})$ & $\uparrow$ & $\downarrow$ & - & $\uparrow$ \\
\end{tabular}


as it can confound the interpretation of other behavioral results. Since anti-aggressive effects were observed at $3 \mathrm{mg} / \mathrm{kg}$ i.p. and increased aggression at the $10 \mathrm{mg} / \mathrm{kg}$ i.p. dose of MPH, it cannot be concluded that any effect on locomotion at these doses altered outcome on aggression. Follow-up experiments should test dosages lower than $3 \mathrm{mg} / \mathrm{kg}$ i.p. that still have aggression-reducing effects without increasing locomotor activity. Furthermore, we demonstrate that the high dose of MPH 24 h later continues to exert a restoration of fear extinction (in the absence of $\mathrm{MPH}$ ), without altering locomotion. In this way, a purely anxiolytic effect is observed compared to vehicle independent of motor function.

\section{U-Shaped Dose Effects of MPH on Aggressive Behavior}

While most of the preclinical literature reports no effect and others show an anti-aggressive effect of MPH (24-26), our experimental settings enabled us to see the effects of MPH in a U-shaped manner. We observed an aggression-reducing effect of MPH when administered in a $3 \mathrm{mg} / \mathrm{kg}$ i.p. dose (i.e., the number of bites, attacks, and threats significantly reduced over time, and the attack latency got longer as well when compared to the vehicle and especially compared to the $10 \mathrm{mg} / \mathrm{kg}$ i.p. dose). On the first injection day, no clear differences were observed between vehicle and the $3 \mathrm{mg} /$ $\mathrm{kg}$ i.p. dose. However, while aggression increased over time for the vehicle group, the level of aggression for the $3 \mathrm{mg} / \mathrm{kg}$ i.p. MPHtreated group remained more similar between testing days with regard to bites and attacks and even reduced for the number of observed threats, indicating a long-lasting effect of MPH. The 10 $\mathrm{mg} / \mathrm{kg}$ i.p. MPH dose directly increased aggression on the first day, and this level remained the same on the last day, which was comparable to the level of aggression seen in the vehicle-treated group. Therefore, it can be argued that the $10 \mathrm{mg} / \mathrm{kg}$ i.p. dose increases aggression during the first resident-intruder interaction and appears to have no additional effect on aggression on the fifth day. While the $3 \mathrm{mg} / \mathrm{kg}$ i.p. dose does not have a direct effect on day 1 , it is associated with a prolonged effect on attack latencies later on. The average attack latency of the last three interactions was significantly longer for the animals treated with $3 \mathrm{mg} / \mathrm{kg} \mathrm{MPH}$ in comparison to both vehicle-treated and $10 \mathrm{mg} / \mathrm{kg}$ i.p. MPHtreated animals. Moreover, the number of attacks and threats were reduced in the animals treated with $3 \mathrm{mg} / \mathrm{kg}$ i.p. $\mathrm{MPH}$ on the last interaction day. This decrease in aggression could be caused by a reduction in social interest (or an increase in social trust) that we found in the social interaction test in BALB/cJ mice treated with 3 $\mathrm{mg} / \mathrm{kg} \mathrm{MPH}$. Whether this is related to the state of anxiety remains unclear and needs to be investigated in more detail. While an increase in aggressiveness is not often reported as a consequence of $\mathrm{MPH}$ administration in rodents, an increase of aggressive behavior has been reported in humans as one of the side effects of $\mathrm{MPH}$ when it is administrated above the therapeutic window, probably as a result of inducing excessive increases in dopamine (DA) and noradrenaline (NA) levels $(15,45)$. Excessive DA and NA tone could bind to a larger population of DA and NA receptors, could increase the burden on monoamine reuptake transporters, and may even have spillover effects via volume transmission. Use of $\mathrm{MPH}$ outside the therapeutic window, due to therapeutic errors, accidental misdosage, misuse, or abuse may cause adverse effects that include irritability and agitation in a dose-dependent manner $(46,47)$. However, these adverse effects may be context dependent (48). While these effects are often observed in the clinic, they are rarely described in the literature (49). Therefore, we may assume the $10 \mathrm{mg} / \mathrm{kg}$ dose, which was given to BALB/cJ mice in our study, is outside the therapeutic window.

The U-shaped dose-response curve on aggression that we observed after administration of MPH may be related to differential effects on both DA and NA. In humans, MPH has a 50 -fold lower effective dose for the noradrenaline transporter than for the DA transporter (50). A low dose of MPH $(2.0 \mathrm{mg} / \mathrm{kg}$ p.o.; $0.25-1.0 \mathrm{mg} / \mathrm{kg}$ i.p.) has been shown to increase prefrontal cortex-dependent cognitive functioning by increasing both NA and DA efflux, without increasing locomotion. However, outside the prefrontal complex (PFC), these small doses had minimal impact on NA and DA release (51). With regard to NA, it is thought that the level of NA release determines which type of adrenoreceptor is activated. Moderate levels are thought to bind to high-affinity alpha-2a adrenergic receptors, whereas higher levels could also engage the lower-affinity alpha- 1 and beta- 1 adrenergic receptors (52). Studies that tested atomoxetine, a non-stimulant drug and selective NA reuptake inhibitor, show decreased anxiety (effect size 1.51, 53) and decreased aggression (effect size $0.52-1.10,54,55$ ) after treatment in children with ADHD and comorbid disorders (e.g., anxiety disorder and oppositional defiant disorder; 56, 57). NA reuptake inhibitors (such as atomoxetine) have been demonstrated to increase DA levels in the PFC but not in the striatum and nucleus accumbens (58), while MPH administration increased DA levels in all these areas $(59,60)$. This may indicate that the aggression- and anxietyreducing effects of $\mathrm{MPH}$ may be associated with the increase of NA or DA release specifically in the PFC.

We observed that administration of $10 \mathrm{mg} / \mathrm{kg}$ i.p. MPH causes the opposite effect (increased aggression), and excessive levels of DA and NA, caused by this higher dose of MPH, could have potentially driven the animal to a hyperarousal state $(20$, $52,61)$. In addition, the high dose may also have activated other lower-affinity targets (e.g. the serotonin transporter; 62) that may have non-specific effects on the behavioral outcome by altering non-noradrenergic/non-dopaminergic mechanisms. It may be that MPH improves anxiety symptoms via the improvement of other ADHD symptoms such as attention (63), which together impact aggression by changing social attention. While an inverted U-shaped response of stimulant treatment has been demonstrated on attentional and working memory measures in both animals $(64,65)$ and humans $(66)$, no preclinical study has shown a U-shaped dose effect of MPH on aggression before. Dissecting out the relative contribution of DA and NA receptor subtypes to the behavioral profiles of the 3 and $10 \mathrm{mg} / \mathrm{kg}$ i.p. $\mathrm{MPH}$ dose in BALB/cJ mice may be a useful next step.

\section{CONCLUSIONS}

This study has investigated the effect of MPH on anxiety, fear extinction, and social behaviors including aggression in 
the $\mathrm{BALB} / \mathrm{cJ}$ mouse. Independent of the dose, $\mathrm{MPH}$ reduced anxiety, whereas its effect on conditioned fear (decreased) was dose dependent. In addition, we found a differential effect of $\mathrm{MPH}$ on aggression in a dose-dependent manner. Specifically, administration of $3 \mathrm{mg} / \mathrm{kg} \mathrm{MPH}$ i.p. prevented aggression escalation over time, while the $10 \mathrm{mg} / \mathrm{kg}$ i.p. dose increased the levels of aggression. This research may contribute to a better understanding of the efficacy of $\mathrm{MPH}$ administration and assist in understanding its potential impact in the clinical management of conduct problems and callous unemotional traits.

\section{DATA AVAILABILITY STATEMENT}

The datasets generated for this study are available on request to the corresponding author.

\section{ETHICS STATEMENT}

The animal study was reviewed and approved by the Committee for Animal Experiments of the Radboud University Medical Center, Nijmegen, The Netherlands under project number: DEC2013-235.

\section{REFERENCES}

1. Loeber R, Burke JD, Lahey BB, Winters A, Zera M. Oppositional defiant and conduct disorder: a review of the past 10 years, part I. J Am Acad Child Adolesc Psychiatry (2000) 39(12):1468-84. doi: 10.1097/00004583-200012000-00007

2. Gadow KD, Nolan EE, Sverd J, Sprafkin J, Schwartz J. Anxiety and depression symptoms and response to methylphenidate in children with attentiondeficit hyperactivity disorder and tic disorder. J Clin Psychopharmacol (2002) 22(3):267-74. doi: 10.1097/00004714-200206000-00007

3. Spencer TJ, Biederman J, Mick E. Attention-deficit/hyperactivity disorder: diagnosis, lifespan, comorbidities, and neurobiology. J Pediatr Psychol (2007) 32(6):631-42. doi: 10.1093/jpepsy/jsm005

4. Blader JC, Pliszka SR, Kafantaris V, Foley CA, Crowell JA, Carlson GA, et al. Callous-unemotional traits, proactive aggression, and treatment outcomes of aggressive children with attention-deficit/hyperactivity disorder. J Am Acad Child Adolesc Psychiatry (2013) 52(12):1281-93. doi: 10.1016/j.jaac.2013.08.024

5. Gurnani T, Ivanov I, Newcorn JH. Pharmacotherapy of aggression in child and adolescent psychiatric disorders. J Child Adolesc Psychopharmacol (2016) 26(1):65-73. doi: 10.1089/cap.2015.0167

6. Barzman DH, Findling RL. Pharmacological treatment of pathologic aggression in children. Int Rev Psychiatry (2008) 20(2):151-7. doi: $10.1080 / 09540260801887819$

7. Lettinga JR, Drent C, Hoekstra PJ, Buitelaar JK, Glennon JC. Clinical pharmacology of conduct disorder: a critical review. Child Adolesc Psychopharmacol News (2011) 16(6):1-10. doi: 10.1521/capn.2011.16.6.1

8. Patel BD, Barzman DH. Pharmacology and pharmacogenetics of pediatric ADHD with associated aggression: a review. Psychiatr Q (2013) 84(4):40715. doi: 10.1007/s11126-013-9253-7

9. Balia C, Carucci S, Coghill D, Zuddas A. The pharmacological treatment of aggression in children and adolescents with conduct disorder. Do callousunemotional traits modulate the efficacy of medication? Neurosci Biobehav $\operatorname{Rev}(2017)$ 91, 218-238. doi: 10.1016/j.neubiorev.2017.01.024

10. Pliszka S. Practice parameter for the assessment and treatment of children and adolescents with attention-deficit/hyperactivity disorder. $J$ Am Acad Child Adolesc Psychiatry (2007) 46(7):894-921. doi: 10.1097/ chi.0b013e318054e724

\section{AUTHOR CONTRIBUTIONS}

AJ and JG were involved in the study conception. AJ, DK and FG performed the experiments. AJ, DK, FG, JB, TK and JG were involved in the data analysis and interpretation. AJ, JB, TK and JG were involved in the preparation and finalisation of the manuscript for publication.

\section{FUNDING}

The research leading to these results has received funding from the European Community's Seventh Framework Programme (FP7/2007-2013) under grant agreement nos. 603016 (MATRICS), 278948 (TACTICS), and 602805 (Aggressotype) and Horizon 2020 Research and Innovation Programme under grant no. 728018 (Eat2beNice).

\section{SUPPLEMENTARY MATERIAL}

The Supplementary Material for this article can be found online at: https://www.frontiersin.org/articles/10.3389/fpsyt.2019.00768/ full\#supplementary-material

11. The National Institute for Health and Care Excellence. Attention deficit hyperactivity disorder: diagnosis and management (NICE Guideline no. 87) (2018). Retrieved from: https://www.nice.org.uk/guidance/ng87

12. Connor DF, Glatt SJ, Lopez ID, Jackson D, Melloni RH. Psychopharmacology and aggression. I: a meta-analysis of stimulant effects on overt/covert aggression-related behaviors in ADHD. J Am Acad Child Adolesc Psychiatry (2002) 41(3):253-61. doi: 10.1097/00004583-200203000-00004

13. Pappadopulos E, Woolston S, Chait, A, Perkins M, Connor DF, Jensen PS. Pharmacotherapy of aggression in children and adolescents: efficacy and effect size. J Can Acad Child Adolesc Psychiatry (2006) 15(1):27-39.

14. Klein RG, Abikoff H, Klass E, Ganeles, D, Seese LM, Pollack S. Clinical efficacy of methylphenidate in conduct disorder with and without attention deficit hyperactivity disorder. Arch Gen Psychiatry (1997) 54(12):1073-80. doi: 10.1001/archpsyc.1997.01830240023003

15. Storebø OJ, Ramstad E, Krogh HB, Nilausen TD, Skoog M, Holmskov M, et al. Methylphenidate for children and adolescents with attention deficit hyperactivity disorder (ADHD). Cochr Database Syst Rev (2015) 351:h5203, 1-14. doi: 10.1002/14651858.CD009885.pub2

16. Pliszka SR. Effect of anxiety on cognition, behavior, and stimulant response in ADHD. J Am Acad Child Adolesc Psychiatry (1989) 28(6):882-7. doi: 10.1097/00004583-198911000-00012

17. Tannock R, Ickowicz A, Schachar R. Differential effects of methylphenidate on working memory in ADHD children with and without comorbid anxiety. J Am Acad Child Adolesc Psychiatry (1995) 34(7):886-96. doi: 10.1097/00004583-199507000-00012

18. Segev A, Gvirts HZ Strouse K, Mayseless N, Gelbard H, Lewis YD, et al. A possible effect of methylphenidate on state anxiety: a single dose, placebo controlled, crossover study in a control group. Psychiatry Res (2016) 241:232-5. doi: 10.1016/j.psychres.2016.05.009

19. Snircova E, Marcincakova-Husarova V, Hrtanek I, Kulhan T, Ondrejka I, Nosalova G. Anxiety reduction on atomoxetine and methylphenidate medication in children with ADHD. Pediatr Int (2016) 58(6):476-81. doi: 10.1111/ped.12847

20. Sprague RL, Sleator EK. Methylphenidate in hyperkinetic children: differences in dose effects on learning and social behavior. Science (1977) 198(4323):1274-6. doi: 10.1126/science.337493 
21. Carmack SA, Howell KK, Rasaei K, Reas ET, Anagnostaras SG. Animal model of methylphenidate's long-term memory-enhancing effects. Learn Mem (2014) 21(2):82-9. doi: 10.1101/lm.033613.113

22. Stein MA, Sarampote CS, Waldman ID, Robb AS, Conlon C, Pearl PL, et al. A dose-response study of OROS methylphenidate in children with attentiondeficit/hyperactivity disorder. Pediatrics (2003) 112(5):e404. doi: 10.1542/ peds.112.5.e404

23. Barkley RA, DuPaul GJ, McMurray MB. Attention deficit disorder with and without hyperactivity: clinical response to three dose levels of methylphenidate. Pediatrics (1991) 87(4):519-31. doi: 10.1037/e338612004-007

24. ValzelliL, GiacaloneE, GarattiniS. Pharmacological control of aggressive behavior in mice. Eur J Pharmacol (1967) 2(2):144-6. doi: 10.1016/0014-2999(67)90040-4

25. Miczek KA, O’Donnell JM. Intruder-evoked aggression in isolated and nonisolated mice: effects of psychomotor stimulants and L-dopa. Psychopharmacology (Berl) (1978) 57(1):47-55. doi: 10.1007/BF00426957

26. Koike H, Ibi D, Mizoguchi H, Nagai T, Nitta A, Takuma K, et al. Behavioral abnormality and pharmacologic response in social isolation-reared mice. Behav Brain Res (2009) 202(1):114-21. doi: 10.1016/j.bbr.2009.03.028

27. Abraham AD, Cunningham CL, Lattal KM. Methylphenidate enhances extinction of contextual fear. Learn Mem (2012) 19(2):67-72. doi: 10.1101/ $\operatorname{lm} .024752 .111$

28. Fairless AH, Dow HC, Toledo MM, Malkus KA, Edelmann M, Li H, et al. Low sociability is associated with reduced size of the corpus callosum in the BALB/cJ inbred mouse strain. Brain Res (2008) 1230:211-7. doi: 10.1016/j. brainres.2008.07.025

29. Velez L, Sokoloff G, Miczek KA, Palmer AA, Dulawa SC. Differences in aggressive behavior and DNA copy number variants between BALB/cJ and BALB/cByJ substrains. Behav Genet (2010) 40(2):201-10. doi: 10.1007/ s10519-009-9325-5

30. Jager A, Amiri H, Bielczyk N, van Heukelum S, Heerschap A, Aschrafi A, et al. Cortical control of aggression: GABA signalling in the anterior cingulate cortex. Eur Neuropsychopharmacol (2017) In Press. doi: 10.1016/j. euroneuro.2017.12.007

31. Pillidge K, Porter AJ, Young JW, Stanford SC. Perseveration by NK1R/- ('knockout') mice is blunted by doses of methylphenidate that affect neither other aspects of their cognitive performance nor the behaviour of wild-type mice in the 5-Choice Continuous Performance Test. J Psychopharmacol (Oxford, England) (2016) 30(9):837-47. doi: $10.1177 / 0269881116642541$

32. Gerasimov MR, Franceschi M, Volkow ND, Rice O, Schiffer WK, Dewey SL. Synergistic interactions between nicotine and cocaine or methylphenidate depend on the dose of dopamine transporter inhibitor. Synapse (2000) 38(4):4327. doi: 10.1002/1098-2396(20001215)38:4<432::AID-SYN8>3.0.CO;2-Q

33. Sadasivan S, Pond BB, Pani AK, Qu C, Jiao Y, Smeyne RJ. Methylphenidate exposure induces dopamine neuron loss and activation of microglia in the basal ganglia of mice. PLoS One (2012) 7(3):e33693. doi: 10.1371/journal. pone.0033693

34. Koolhaas JM, Schuurman T, Wiepkema PR. The organization of intraspecific agonistic behaviour in the rat. Progress in Neurobiology (1980) 15(3):247-68. doi: 10.1016/0301-0082(80)90024-6

35. Koolhaas JM, Coppens CM, de Boer SF, Buwalda B, Meerlo P, Timmermans PJ. The resident-intruder paradigm: a standardized test for aggression, violence and social stress. J Vis Exp (2013) (77), e4367. doi: 10.3791/4367

36. Tukey J. Exploratory data analysis. Reading, Massachusetts, USA: AddisonWesley Reading (1977).

37. Tilley MR, Gu HH. The effects of methylphenidate on knockin mice with a methylphenidate-resistant dopamine transporter. J Pharmacol Exp Ther (2008) 327(2):554-60. doi: 10.1124/jpet.108.141713

38. Heredia L, Torrente M, Colomina MT, Domingo JL. Assessing anxiety in C57BL/6J mice: a pharmacological characterization of the zero maze test. J Pharmacol Toxicol Methods (2013) 68(2):275-83. doi: 10.1016/j. vascn.2013.02.010

39. Heredia L, Torrente M, Colomina MT, Domingo JL. Assessing anxiety in C57BL/6J mice: a pharmacological characterization of the open-field and light/dark tests. J Pharmacol Toxicol Methods (2014) 69(2):108-14. doi: 10.1016/j.vascn.2013.12.005
40. An XL, Zou JX, Wu RY, Yang Y, Tai FD, Zeng SY, et al. Strain and sex differences in anxiety-like and social behaviors in C57BL/6J and BALB/cJ mice. Exp Anim (2011) 60(2):111-23. doi: 10.1538/expanim.60.111

41. Aga-Mizrachi S, Cymerblit-Sabba A, Gurman O, Balan A, Shwam G, Deshe R, et al. Methylphenidate and desipramine combined treatment improves PTSD symptomatology in a rat model. Transl Psychiatry (2014) 4:e447. doi: 10.1038/tp.2014.82

42. Furini CRG, Behling JAK, Zinn CG, Zanini ML, Assis Brasil E, Pereira LD, et al. Extinction memory is facilitated by methylphenidate and regulated by dopamine and noradrenaline receptors. Behav Brain Res (2017) 326:303-6. doi: 10.1016/j.bbr.2017.03.027

43. Penner MR, McFadyen MP, Carrey N, Brown RE. Effects of chronic and acute methylphenidate hydrochloride (Ritalin) administration on locomotor activity, ultrasonic vocalizations, and neuromotor development in 3- to 11-day-old CD-1 mouse pups. Dev Psychobiol (2001) 39(3):216-28. doi 10.1002/dev.1047

44. Yang PB, Swann AC, Dafny N. Dose-response characteristics of methylphenidate on locomotor behavior and on sensory evoked potentials recorded from the VTA, NAc, and PFC in freely behaving rats. Behav Brain Funct (2006) 2:3. doi: 10.1186/1744-9081-2-3

45. Aman MG, Kern RA, McGhee DE, Arnold LE. Fenfluramine and methylphenidate in children with mental retardation and ADHD: clinical and side effects. J Am Acad Child Adolesc Psychiatry (1993) 32(4):851-9. doi: 10.1097/00004583-199307000-00022

46. Morton WA, Stockton GG. Methylphenidate abuse and psychiatric side effects. Prim Care Companion J Clin Psychiatry (2000) 2(5):159-64. doi: 10.4088/PCC.v02n0502

47. Klein-Schwartz W. Abuse and toxicity of methylphenidate. Curr Opin Pediatr (2002) 14(2):219-23. doi: 10.1097/00008480-200204000-00013

48. Kuypers K, Verkes RJ, van den Brink W, van Amsterdam J, Ramaekers JG. Intoxicated aggression: Do alcohol and stimulants cause dose-related aggression? A review. Eur Neuropsychopharmacol (2018) In Press. doi: 10.1016/j.euroneuro.2018.06.001

49. Konrad-Bindl DS, Gresser U, Richartz BM. Changes in behavior as side effects in methylphenidate treatment: review of the literature. Neuropsychiatr Dis Treat (2016) 12:2635-47. doi: 10.2147/NDT.S114185

50. Hannestad J, Gallezot JD, Planeta-Wilson B, Lin SF, Williams WA, van Dyck $\mathrm{CH}$, et al. Clinically relevant doses of methylphenidate significantly occupy norepinephrine transporters in humans in vivo. Biol Psychiatry (2010) 68(9):854-60. doi: 10.1016/j.biopsych.2010.06.017

51. Berridge CW, Devilbiss DM, Andrzejewski ME, Arnsten AF, Kelley AE, Schmeichel, B, et al. Methylphenidate preferentially increases catecholamine neurotransmission within the prefrontal cortex at low doses that enhance cognitive function. Biol Psychiatry (2006) 60(10):1111-20. doi: 10.1016/j. biopsych.2006.04.022

52. Arnsten AF. Catecholamine and second messenger influences on prefrontal cortical networks of "representational knowledge": a rational bridge between genetics and the symptoms of mental illness. Cereb Cortex (2007) 17 :i6-15. doi: 10.1093/cercor/bhm033

53. Gabriel A, Violato C. Adjunctive atomoxetine to SSRIs or SNRIs in the treatment of adult ADHD patients with comorbid partially responsive generalized anxiety (GA): an open-label study. Attention Deficit Hyperactivity Disord (2011) 3(4):319-26. doi: 10.1007/s12402-011-0063-1

54. Dell'Agnello G, Maschietto D, Bravaccio C, Calamoneri F, Masi G, Curatolo P, et al. Atomoxetine hydrochloride in the treatment of children and adolescents with attention-deficit/hyperactivity disorder and comorbid oppositional defiant disorder: a placebo-controlled Italian study. Eur Neuropsychopharmacol (2009) 19(11):822-34. doi: 10.1016/j.euroneuro.2009.07.008

55. Holzer B, Lopes V, Lehman R. Combination use of atomoxetine hydrochloride and olanzapine in the treatment of attention-deficit/hyperactivity disorder with comorbid disruptive behavior disorder in children and adolescents 10-18 years of age. J Child Adolesc Psychopharmacol (2013) 23(6):415-8. doi: 10.1089/ cap.2013.0029

56. Hutchison SL, Ghuman JK, Ghuman HS, Karpov I, Schuster JM. Efficacy of atomoxetine in the treatment of attention-deficit hyperactivity disorder in patients with common comorbidities in children, adolescents and 
adults: a review. Ther Adv Psychopharmacol (2016) 6(5):317-34. doi: $10.1177 / 2045125316647686$

57. Griffiths KR, Leikauf JE, Tsang TW, Clarke S, Hermens DF, Efron D, et al. Response inhibition and emotional cognition improved by atomoxetine in children and adolescents with ADHD: the ACTION randomized controlled trial. J Psychiatr Res (2018) 102:57-64. doi: 10.1016/j.jpsychires.2018.03.009

58. Carboni E, Tanda GL, Frau R, Di Chiara G. Blockade of the noradrenaline carrier increases extracellular dopamine concentrations in the prefrontal cortex: evidence that dopamine is taken up in vivo by noradrenergic terminals. J Neurochem (1990) 55(3):1067-70. doi: 10.1111/j.14714159.1990.tb04599.x

59. Bymaster FP, Katner JS, Nelson DL, Hemrick-Luecke SK, Threlkeld PG, Heiligenstein $\mathrm{JH}$, et al. Atomoxetine increases extracellular levels of norepinephrine and dopamine in prefrontal cortex of rat: a potential mechanism for efficacy in attention deficit/hyperactivity disorder. Neuropsychopharmacology (2002) 27(5):699-711. doi: 10.1016/ S0893-133X(02)00346-9

60. Gamo NJ, Wang M, Arnsten AFT. Methylphenidate and atomoxetine enhance prefrontal function through a2-adrenergic and dopamine D1 receptors. J Am Acad Child Adolesc Psychiatry (2010) 49(10):1011-23. doi: 10.1016/j.jaac.2010.06.015

61. Berridge CW, Arnsten AF. Psychostimulants and motivated behavior: arousal and cognition. Neurosci Biobehav Rev (2013) 37(9 Pt A):1976-84. doi: 10.1016/j.neubiorev.2012.11.005

62. Han DD, Gu HH. Comparison of the monoamine transporters from human and mouse in their sensitivities to psychostimulant drugs. BMC Pharmacol (2006) 6:6. doi: 10.1186/1471-2210-6-6

63. Coughlin CG, Cohen SC, Mulqueen JM, Ferracioli-Oda E, Stuckelman ZD, Bloch MH. Meta-analysis: reduced risk of anxiety with psychostimulant treatment in children with attention-deficit/hyperactivity disorder. $J$ Child Adolesc Psychopharmacol (2015) 25(8):611-7. doi: 10.1089/cap.2015.0075

64. Zahrt J, Taylor JR, Mathew RG, Arnsten AF. Supranormal stimulation of D1 dopamine receptors in the rodent prefrontal cortex impairs spatial working memory performance. J Neurosci (1997) 17(21):8528-35. doi: 10.1523/ JNEUROSCI.17-21-08528.1997

65. Granon S, Passetti F, Thomas KL, Dalley JW, Everitt BJ, Robbins TW. Enhanced and impaired attentional performance after infusion of D1 dopaminergic receptor agents into rat prefrontal cortex. J Neurosci (2000) 20(3):1208-15. doi: 10.1523/JNEUROSCI.20-03-01208.2000

66. Gibbs SE, D'Esposito M. A functional magnetic resonance imaging study of the effects of pergolide, a dopamine receptor agonist, on component processes of working memory. Neuroscience (2006) 139(1):359-71. doi: 10.1016/j.neuroscience.2005.11.055

Conflict of Interest: The authors declare that the research was conducted in the absence of any commercial or financial relationships that could be construed as a potential conflict of interest.

The handling editor declared a shared affiliation, though no other collaboration, with the authors.

Copyright $\odot 2019$ Jager, Kanters, Geers, Buitelaar, Kozicz and Glennon. This is an open-access article distributed under the terms of the Creative Commons Attribution License (CC BY). The use, distribution or reproduction in other forums is permitted, provided the original author(s) and the copyright owner(s) are credited and that the original publication in this journal is cited, in accordance with accepted academic practice. No use, distribution or reproduction is permitted which does not comply with these terms. 